\title{
Development of Tools for DER Components in a Distribution Network
}

\author{
Mihet-Popa, Lucian; Koch-Ciobotaru, C; Isleifsson, Fridrik Rafn; Bindner, Henrik W.
}

Published in:

Proceedings of the 20th International Conference on Electrical Machines

Link to article, DOI:

10.1109/ICEIMach.2012.6350168

Publication date:

2012

Document Version

Publisher's PDF, also known as Version of record

Link back to DTU Orbit

Citation (APA):

Mihet-Popa, L., Koch-Ciobotaru, C., Isleifsson, F. R., \& Bindner, H. W. (2012). Development of Tools for DER Components in a Distribution Network. In Proceedings of the 20th International Conference on Electrical Machines https://doi.org/10.1109/ICEIMach.2012.6350168

\section{General rights}

Copyright and moral rights for the publications made accessible in the public portal are retained by the authors and/or other copyright owners and it is a condition of accessing publications that users recognise and abide by the legal requirements associated with these rights.

- Users may download and print one copy of any publication from the public portal for the purpose of private study or research.

- You may not further distribute the material or use it for any profit-making activity or commercial gain

- You may freely distribute the URL identifying the publication in the public portal 


\title{
Development of Tools for DER Components in a Distribution Network
}

\author{
L. Mihet-Popa, C. Koch-Ciobotaru, F. Isleifsson and H. Bindner
}

\begin{abstract}
The increasing amount of Distributed Energy Resources (DER) components into distribution networks involves the development of accurate simulation models that take into account an increasing number of factors that influence the output power from the DG systems. This paper presents two simulation models: a PV system model using the single-diode four-parameter model based on data sheet values and a Vanadium Redox Battery (VRB) system model based on the efficiency of different components and the power losses. The unit models were implemented first in MATLAB/Simulink and the simulation results have been compared with the data sheet values and with the characteristics of the units. To point out the strong dependency on ambient conditions and to validate the simulation models a complex data processing subsystem model has also been developed. A PV and a VRB inverter models have also been developed and implemented in PowerFactory to study load flow, steady-state voltage stability and dynamic behavior of a distribution system.
\end{abstract}

Index Terms--distributed energy resources-DER; distributed generation-DG; incidence and tilt angle; micro-grid; PV panels; solar radiation; state of charge (SOC);vanadium redox battery-VRB;

\section{NOMENCLATURE}

$A$ : diode quality factor; $G_{a}$ : solar irradiance; $I_{0}, I_{s c}$ : open circuit and short circuit currents; $I_{m p p}, P_{m p p}, V_{m p p}$ : maximum power point of current, power and voltage; NOCT: nominal operating conditions; $n_{p s}, n_{s}, n_{s p}$ : no. of panels in series, no of cells in series in one panel and no. of strings in parallel; $R_{s}$ : series resistance; $T_{a}, T_{\text {cell }}$ : ambient and cell temperature; $V_{o c}$, $V_{T}$ : open circuit and junction thermal voltage; $W_{s}$ : wind speed; $\alpha$ : solar altitude angle; $\alpha_{\mathrm{s}}$ : solar azimuth angle; $\alpha_{\mathrm{w}}$ : azimuth angle; $\beta$ : panel tilt angle; $\beta_{\mathrm{I}}$ : temperature coefficient for change in $I_{s c} ; \varphi$ : location latitude; $\delta$ : solar declination angle; $\omega$ : mounting coefficient.

\section{INTRODUCTION}

$\mathrm{R}$ enewable energy systems are expanding due to not only environmental aspect but also due to social, economical and political interest. The European Union is aiming at a specific $\mathrm{CO}_{2}$ reduction in the electricity sector in the near future $(20 \%$ reduction by 2020$)$. This will involve a significant growth of PV installation all over Europe resulting in a few hundred GW of capacity [1].

The increased PV capacity will influence power system operation and design. Power supplied from a PV array depends mostly on present ambient conditions such as:

This work was supported in part by the E.U. Project-Smooth PV, No. $10580 / 2011-2012$ and also partially supported by the strategic grant POSDRU/88/1.5/S/50783 of the Ministry of Labor, Family and Social Protection, Romania, co-financed by the EU Social Fund - Investing in people.

L. Mihet-Popa, F. Isleiffson and H. Bindner are with the Department of Electrical Engineering, Danish Technical University-DTU, 4000 Roskilde, Denmark (e-mail:1mih@elektro.dtu.dk).

C. Koch-Ciobotaru is with POLITEHNICA University of Timisoara, Romania (e-mail: cosmin.koch@aut.upt.ro). irradiation and temperature [2-5].

PV output voltage changes mainly with temperature while PV output current changes mainly with irradiation. Therefore in order to develop a very precise simulation model the local wind speed and the solar radiation incidence angle, in terms of the slope and surface azimuth, should be considered [5]-[8].

In order to determine the hourly incident radiation on a surface of any orientation it is necessary to evaluate the ratio of incident radiation on the tilted surface to that on a horizontal surface considering beam, sky diffuse and ground reflected radiation separately [3], [6], [9].

Increased distributed generation is becoming more important in the current power system and in the future it will rely more on distributed energy resources and microgrids. The flexible micro-grid has to be able to import/export energy from/to the grid, control the active and reactive power flows and manage of the storage energy [7], [10].

The battery package is an interesting option for storing excess energy from the hybrid grid (wind intermittency) for later use. It may also act as a peak shaving unit and thereby contribute to a stronger grid [13], [15]-[17].

This paper proposes the development of simulation tools to analyze and simulate power systems with renewable energy sources and electricity storage devices. The tools are based on models implemented first in MATLAB-Simulink and validated by measurements. The paper focuses on simulation models of a small-scale PV System and on a VRB system connected to a micro-grid and on improvements and validating it using experimental facility of an active and distributed power systems laboratory called SYSLAB. In order to find out the differences between DER components in power systems and to study the impact on bus voltage and frequency the systems have also been implemented in DIgSILENT PowerFactory.

\section{DistribUted ENERGY SYSTEM ARCHITECTURE. EXPERIMENTAL FACILITY-SYSLAB}

SYSLAB is a laboratory for research in distributed control and smart grids with a high share of renewable energy production. Its experimental facility is a Wind/PV/Diesel Hybrid Mini-Grid with local storage and a novel control infrastructure. The facility is spread across three sites located several hundred meters apart, as can be seen in Fig. 1a).

It includes two wind turbines $(11 \mathrm{~kW}$ and $55 \mathrm{~kW})$, a PVplant $(7.8 \mathrm{~kW})$, a diesel gen-set $(48 \mathrm{~kW} / 60 \mathrm{kVA})$, an intelligent office building with controllable loads $(20 \mathrm{~kW})$, a number of loads $(75 \mathrm{~kW}, 3 * 36 \mathrm{~kW})$ and a Vanadium Battery of $15 \mathrm{~kW} / 190 \mathrm{kWh}$. At each of the three sites there is a switchboard that allows the components installed at the site to be connected to either of two bus bars. The two bus bars at each site are connected to a crossbar switchboard allowing the flexible setup of the system(s) to be studied. The bus bars can be either connected to the national grid or can be part of 
an isolated system. It allows components and systems to be in grid connected operation, island operation, or operation in parallel with wind turbine or PV-plant, as it is shown in Fig. $1 b)$.

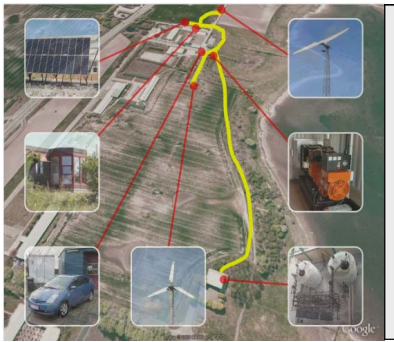

a)

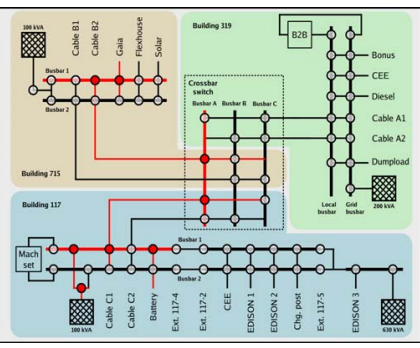

b)
Fig. 1. a) SYSLAB Risø's new laboratory for intelligent, active and distributed power systems and b) details about SYSLAB Micro-Grid architecture.

The components are all connected in one distributed control and measurement system that enables very flexible setup with respect to experimental configuration.

\section{A. PV Panel System}

The PV panels are mounted in three strings: two strings having 18 panels of $165 \mathrm{~W}$ each, and another one containing 12 panels of $100 \mathrm{~W}$ [19]. The strings are connected to the SYSLAB grid through a three-phase PV inverter (SMA Sunny Tripower).

From PV system two sets of data are provided. The first set consists of the ambient measurements from the weather station: solar irradiance on the horizontal, ambient temperature, and wind speed. The second set represents the electric measurements taken from the inverter: the $\mathrm{AC}$ output power to the grid, and on each PV string the DC power, voltage, and current. The two sets of data are read at different sampling frequencies: $1 \mathrm{~Hz}$ for the electrical and $0.1 \mathrm{~Hz}$ for the ambient. These large sets of data are used to develop an accurate model of the existing PV setup and to validate it.

\section{B. Energy Storage System}

The vanadium redox battery system installed in SYSLAB is connected to the grid via a four quadrant power converter and can deliver $15 \mathrm{~kW}$ on the $\mathrm{AC}$ side and the nominal storage capacity is $190 \mathrm{kWh}$. The battery can operate in two modes: P-Q mode (where the active and reactive power of the battery is set by the user) and U-f mode where the power is set according to the grid voltage and frequency and the pre-defined droop-curves [15].

\section{Data Acquisition and Control System}

The data acquisition and control system (hardware and software) is responsible for the supervision and control of the research platform for distributed intelligent energy systems with a high penetration of renewable energy. The supervisory software code was written in Java and is able to manage the data acquisition, processes the data and executes the control loop and outputs the control variables. The sensors outputs are connected to a signal conditioning board, which in turn is connected to the data acquisition (DAQ) board based on a PC (SCADA System).

\section{PV PANEL AND ARRAY MODELING}

\section{A. Modeling of the PV Panel}

To be able to develop an accurate PV panel model it is necessary to define the right equivalent circuit. This paper uses a single diode equivalent circuit for the PV model, described by a simple exponential function:

$$
i=I_{s c}-I_{0} \cdot\left(e^{\left(v+i \cdot R_{s}\right) / n_{s} \cdot V_{T}}-1\right)
$$

Manufacturers typically provide limited operational data for photovoltaic panels. These data are available only at standard rating conditions, for which the irradiance is 1000 $\mathrm{W} / \mathrm{m}^{2}$ and the cell temperature is $25{ }^{\circ} \mathrm{C}$, except for the NOCT which is determined at $800 \mathrm{~W} / \mathrm{m}^{2}$ and an ambient temperature of $20^{\circ} \mathrm{C}$.

Equations for the short circuit current and the open circuit voltage as a function of absolute temperature $\Delta T$ include temperature coefficients that provide the rate of change with respect to temperature of the PV performance parameters, can be express as:

$$
\begin{gathered}
I_{s c}=I_{s c 25} \cdot\left(1+\beta_{I} \cdot \Delta T\right) \\
V_{o c}=V_{o c 25} \cdot(1+\chi \cdot \Delta T) \\
\Delta T=T_{\text {cell }}-T_{a}
\end{gathered}
$$

To complete the model it is also necessary to take into account the variation of the parameters with respect to irradiance:

$$
I_{s c}=I_{s c 25} \cdot\left(G_{a} / 1000\right)
$$

Using a four parameters model of a single diode equivalent circuit, the $\mathrm{v}-\mathrm{i}$ characteristics for a solar panel string depending on irradiance and temperature has the following expressions:

$$
\begin{array}{r}
v=n_{p s} \cdot V_{o c}+n_{p s} \cdot n_{s} \cdot V_{T} \cdot \ln \left(1-i /\left(n_{s p} \cdot I_{s c 25} \cdot G_{a} / 1000\right)\right) \\
i=n_{s p} \cdot I_{s c} \cdot\left(1-e^{\left(v-n_{p s} \cdot V_{o c}+R_{s} \cdot i\right) /\left(n_{p s} \cdot n_{s} \cdot v\right)}\right)
\end{array}
$$

The equations (4) and (5) can be used to calculate the voltage and current over a string of panels.

The model used to obtain the static characteristics of the PV panels has been developed in MATLAB using the equations presented above. The model was developed for one panel, as a function of irradiance and temperature. The model has as inputs $G_{a}$ and $T_{\text {cell }}$ on the panel and it sweeps the voltage range of the PV panel in order to calculate the output current and power. PV cells have nonlinear $\mathrm{i}-\mathrm{v}$ and $\mathrm{p}$ $\mathrm{V}$ characteristics. Its output voltage and power change according to temperature and irradiation.

Fig. 2 shows the typical characteristics for a PV model and also a comparison between PV technical characteristics from datasheet (on the left) and simulation results for one panel.
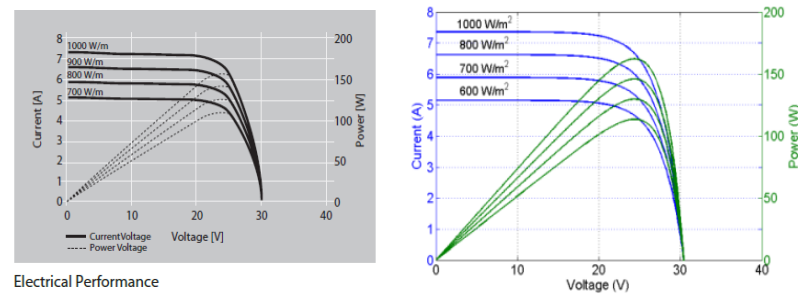

a) 

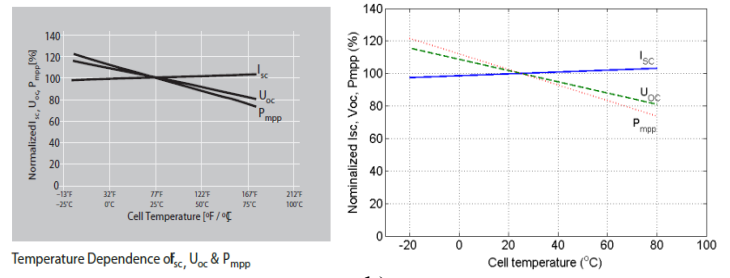

b)
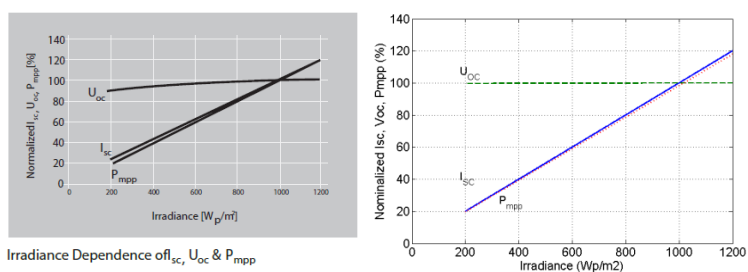

c)

Fig. 2. Comparison between PV technical characteristics from datasheet (on the left) and simulation results for one panel.

\section{B. Modeling of the PV Array}

A Matlab/Simulink model has been developed, based on the equations presented in the last section, in order to reproduce the electrical behavior of the existing PV strings at the SYSLAB experimental facility. The model has the temperature and the solar radiance on the panel as inputs and the $\mathrm{AC}$ power at the inverters' grid side as output.

For obtaining the maximum power of the panel strings, the condition $(\mathrm{dp} / \mathrm{dv}=0)$ should be fulfilled.

The block diagram implemented in Simulink that was developed to implement this model is depicted in Fig. 3.

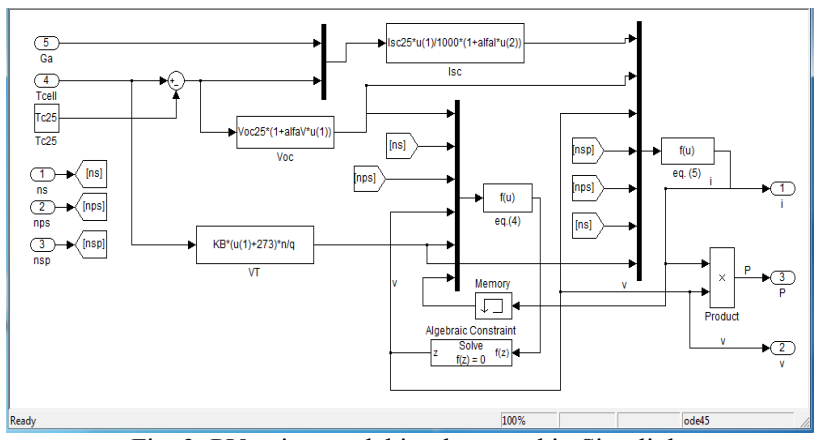

Fig. 3. PV string model implemented in Simulink.

\section{Improvements and Validation of the Model}

Two types of measurements are taken from the experimental facility: ambient measurements from the weather station and electrical measurements taken from the inverter. All these measurements are implemented into our model using a subsystem called "Measurements", as can be seen in Fig. 4.

The three ambient measurements: ambient temperature, horizontal solar radiation, and wind speed are fed to a module/subsystem (called Data Processing in Fig. 4) that calculates the cell temperature of the PV panels and the solar radiation on them, which are the inputs for the PV models together with the number of panels in series, the number of cells in series and the number of strings in parallel.

The simulation model, developed before in MATLAB/Simulink for one PV panel (Fig. 3), has been improved and modified for a PV array with three strings. A block diagram of the model can also be seen in Fig. 4.

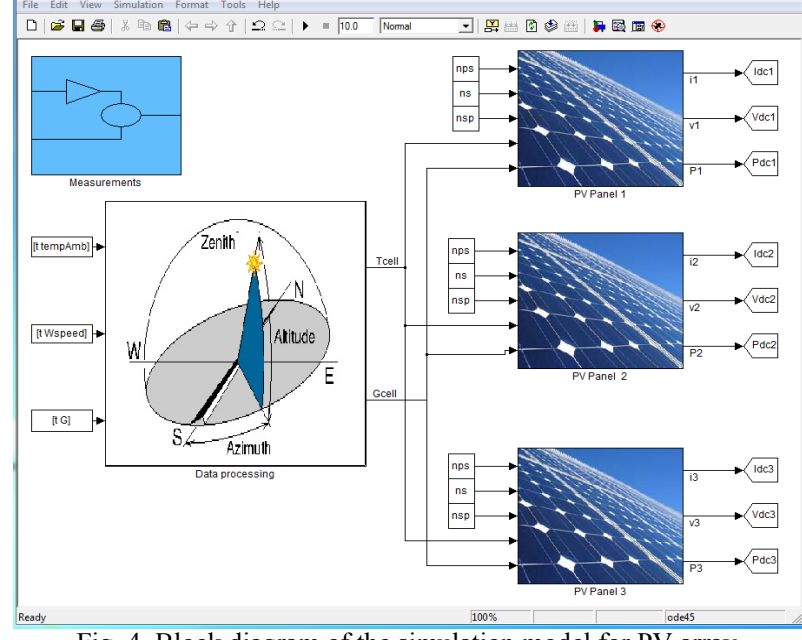

Fig. 4. Block diagram of the simulation model for PV array.

\section{1) Cell Temperature}

The cell temperature $T_{\text {cell }}$ can be very different from the ambient temperature $T_{a}$ and it depends on the solar irradiation $G_{a}, T_{a}$ and also on the wind speed $W_{s}$. Solar irradiation acts on increasing $T_{\text {cell }}$ and the wind speed has a cooling effect and lowers $T_{\text {cell }}$ [3], [5].

If the PV panels are mounted in the regions with high wind potential (as in our case), the wind speed must be considered. The forced (wind) convection is large for high wind speeds and the cell temperature function takes the following form [5]:

$$
T_{\text {cell }}=T_{a}+\omega \cdot\left(0.32 /\left(8.91+2 \cdot W_{s} / 0.67\right)\right) \cdot G_{a}
$$

Where $W_{s}$ is the wind speed measured on horizontal plane and $\omega$ is the mounting coefficient, which depends on the mounting conditions of the PV panels and can be expressed as:

$$
\omega=15^{0} \cdot(\text { SolarNoon }-\Delta T)
$$

The wind that produces the cooling effect through forced convection is the wind parallel to the panel surface; that is why the transformation $W_{\text {sparallel }}=W s / 0.67$ is used.

For a better understanding on the influence of solar irradiance and wind speed on the cell temperature, a graphical representation of these values is depicted in Fig. 5. The differences in temperature of the PV cells according to different considerations are also presented.

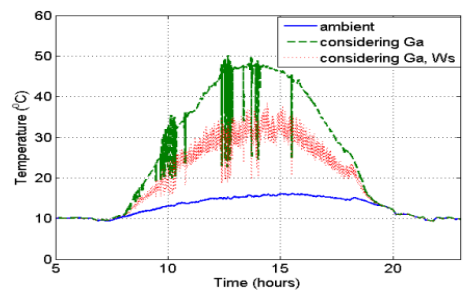

Fig. 5. Ambient measurements and their effect on the PV cell temperature.

The solar irradiance has a high heating effect, at noon it can be seen a $30^{\circ} \mathrm{C}$ increase of cell temperature. Considering also the wind effect, the cell temperature is lowered, at noon, with $12^{\circ} \mathrm{C}$. This change in temperature has an effect on the output power; as shown also in Fig. 2b). At each degree change in temperature, the efficiency modifies with approximately $0.44 \%$ : That means that if the temperature rises, the efficiency decreases and vice versa [20,21].

2) Solar irradiance on the PV panel

As shown in Fig. 2c), the solar radiance has influence 
only on the current and implicitly on the output power of the PV panel, so the plots contain the effect of the change in the input solar irradiance, according to the 'adaptation' of the horizontal solar irradiance to the real case of the PV panel. The solar irradiance input to the model is the horizontal value measured from the weather station. This translates into substantial differences as can also be seen in Fig 5 .

a) Considering the tilt angle of the PV panels

The PV panels from SYSLAB are tilted at $\beta=60^{\circ}$. For introducing this factor into the model, the declination angle $(\delta)$ has to be defined. The declination angle is the angular position of the sun at solar noon with respect to the plane of the equator. Its value is given by [6]:

$$
\delta=23.45 \cdot \sin (360 \cdot(284+n / 365.25))
$$

Where 23.45 is the Tropic of Cancer latitude. For this equation, the days are numbered from the spring equinox (day 81 ) and using the fact that $\sin$ is a periodic function, $365-81=284$.

The relation between solar irradiance on horizontal plane $G_{\text {horiz }}$ and the solar irradiance on a tilted panel, facing south is [6]:

$$
G_{\text {panel }}=\left(G_{\text {horiz }} \cdot \sin (\alpha+\beta)\right) / \sin (\alpha)
$$

In which $\alpha=90-\varphi+\delta$.

From this equation it is clear that the ratio between the solar irradiance on the PV panel and the one on the horizontal changes during the year, as the earth orbits the sun and the declination angle changes with every day. The day number of the considered day for the simulation has to be an input for the model [20].

b) Considering the orientation of the PV panels

For estimating the solar irradiance for a non facing south PV panel from a facing south PV, which the model calculates at this stage, some additional relations have to be introduced, such as: solar hour angle, equation of time and daylights saving time [3]. For calculating the solar irradiation on the PV panels from the solar radiation on a tilted panel, calculated at stage 2 (Fig. 6b), a correction factor was defined as:

$$
G_{\text {corr }}=\cos (\omega) / \cos (\omega-\text { deviation })
$$

In addition to the day's number in the year, the model has to be provided with the local time, as of this $13^{0}$ deviation, the solar irradiance on the PV panel has a nonlinear variation from the measured horizontal solar irradiation according to the position of the sun on the sky in each moment of the day (Fig. 6c).

In Fig. 6 are presented the simulation results versus measurements at different stages of the modeling. These Figures also shows the importance of several factors that have to be taken in consideration, especially PV panel tilt angle and orientation.

In Fig. 6 a) is shown a comparison between measured and simulated output power without considering wind speed effect or any improvements.

Fig. 6 b) shows the same wave form for output power, with the same peak values, and the same changes in power due to shading effect in a synchronous manner. The simulation has a delay of around 50 minutes. This is the effect of the PV panels' orientation, which have a $13^{\circ}$ deviation from the E-W axis.

Considering the tilt angle and orientation, the influence of solar irradiance and wind speed on the cell temperature the measurements and simulations are almost identically, as can be seen in Fig. 6 c).

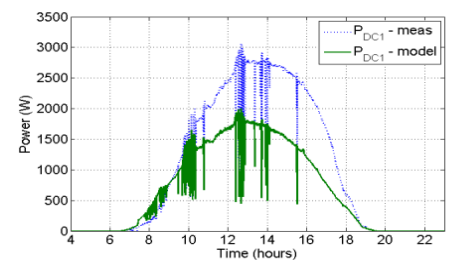

a)

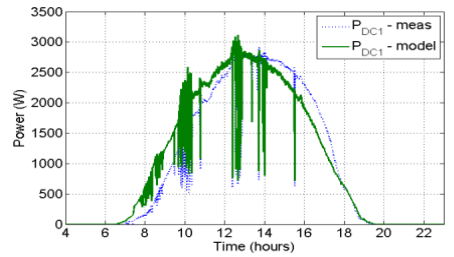

b)

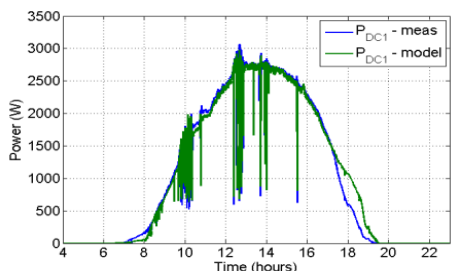

c)

Fig. 6. Solar irradiance adaptation steps.

\section{VRB MODEL IMPLEMENTED IN MATLAB-SIMULINK AND VALIDATED BY MEASUREMENTS}

\section{A. VRB Modeling and Implementation}

The VRB model has been developed in MATLAB/Simulink and is based on the power balance between the input and the stored power considering the efficiency of different components and the power losses, as it is shown in Fig. 7. These characteristics of the battery have been computed based experiments by measuring different electric values at different loads and SOC levels [15].

The simulation model of the battery system contains four subsystems: the power converter, the cell stacks, the energy storage, voltage limitation and the auxiliaries, as it is depicted in Fig. 7 b).

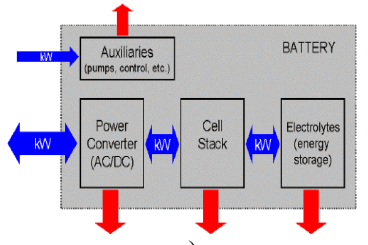

a)

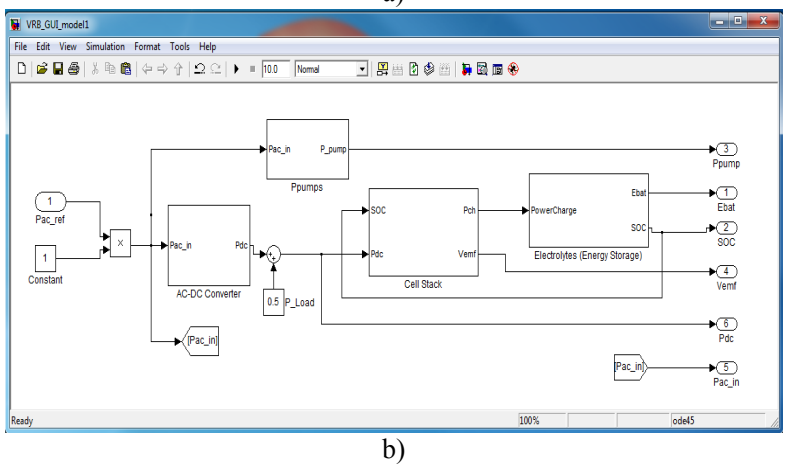

Fig. 7 a) Schematic drawing of the battery system (the red arrows indicate losses from the different parts of the system) and b) Simulink implementation.

The power converter was modeled using a look-up table with the efficiency of the AC-DC converter in charge and 
discharge operation modes.

The efficiency of the cell stacks was implemented as a function of the DC power at different SOC levels, when the battery was running in stable conditions during charge/discharge modes.

The total power available is related to the electrode area in the cell stacks and the total energy stored in the VRB depends on both the SOC and the amount of active chemical substances. The actual energy stored in the battery is defined as:

$$
E_{\text {batt }}=E_{\text {batt } 0}+\int P_{\text {cell }} \cdot d t
$$

Where $E_{\text {batto }}$ is the initial energy stored in the battery and $P_{\text {cell }}$ is the charge/discharge power at the electrolyte side.

The state of charge (SOC) is defined as the amount of energy stored in the battery $\left(E_{\text {batt }}\right)$ divided by the total energy capacity $E_{T}$ :

$$
S O C=E_{\text {batt }} / E_{T}
$$

The energy storage subsystem was implemented based on (11) and (12) having as output $\mathrm{E}_{\mathrm{bat}}$ and SOC.

For a vanadium battery the auxiliary power consumption is significant since the electrolyte has to be circulated for the battery to be operational. The power of the auxiliaries (control system, pumps, etc.) can be derived from the measured AC power of the battery and the total power flow over the bus (when only the battery is connected). When the battery is off, the power consumption (for the control PC and the displays) is $235 \mathrm{~W}$. When the battery is on and the pumps are running the power consumption is between 1.1 and 1.6 $\mathrm{kW}$ depending on the AC power. The auxiliary block has also been modeled by a look-up table considering experimental data from [15].

The voltage limitation block has two functionalities: to calculate the DC side voltage of the converter and to calculate the AC limit power according to the SOC. The power input is physically limited and at high SOC values, the converter is not able to receive the prescribed power, but a limited one. Also the subsystem contains an empirical relation between the SOC and the voltage across the electrolyte $\left(V_{\text {cell }}\right)$, also implemented by a look-up table based on experiments.

\section{B. Comparison between simulation and measurements}

In order to validate the simulation model, measurements were taken from the DAQ board of the VRB, fed into the model and verifying the output values of the battery and of the model.

The following experiment for a time scale of 36 hours was considered: starting from a $\mathrm{SOC}=93.5 \%$ the battery was discharged with a constant power $\mathrm{P}_{\mathrm{AC}}=15 \mathrm{~kW}$, until $\mathrm{SOC}=18 \%$. Then a charge sequence was considered from $\mathrm{SOC}=14 \%$ until the level of $\mathrm{SOC}=87 \%$ at $\mathrm{P}_{\mathrm{AC}}=10 \mathrm{~kW}$.

A comparison between simulations and measurements of SOC level and DC Voltage is presented in Fig. 8. As can be seen it is a very small difference between graphics, which means that the simulation model developed can be an accurate tool for studying and analyzing the characteristics of the energy storage system in a distributed network.

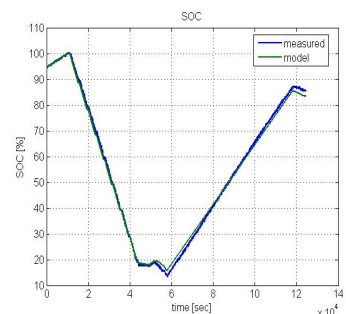

a)

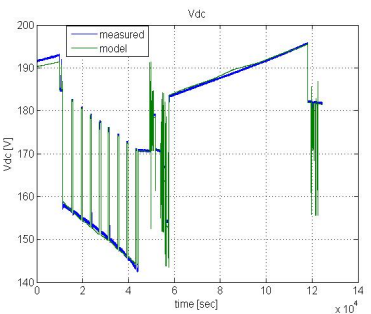

b)
Fig. 8. Comparison between simulations and measurements: a) State of Charge sequence-SOC and b) DC Voltage- $\mathrm{V}_{\mathrm{dc}}$ versus time.

\section{Simulation Model of DER COMPONENTS DEVELOPED IN POWERFACTORY FOR DISTRIBUTION NETWORKS}

Computer models of power systems are widely used by power system utilities to study load flow, steady-state voltage stability and dynamic and transient behavior of power system.

DIgSILENT PowerFactory has been chosen because provides the ability to simulate load flow, RMS fluctuations in the same software environment. It provides a comprehensive library of models for electrical components in the power system [18].

The dynamic models of the PV System and VRB system implemented in PowerFactory has been built with standard components library and are based on the same equations used for MATLAB/Simulink models presented before.

The blocks of the PV system (Fig. 9b), such as: PV model, DC-Link and controller of the Static Generator and of the VRB system (Fig. 9c), such as: battery model, charge and P-Q controllers are implemented in the dynamic simulation language DSL of DIgSILENT. DSL allows the user to implement specific models that are not standard in the DIgSILENT library and thus to create own developed blocks either as modifications of existing models or as completely new models. The internal simulation language DSL has also been used to define the PV and VRB characteristics and to initialize the parameters and variables of the models.

Fig. 9 a) shows a single line diagram of the SYSLAB architecture implemented in PowerFactory. For load flow analysis, also shown in Fig. 9 a), the local voltage controller could be set to three different modes: $\cos \varphi, V$ and droop. For RMS and EMT simulations the static generator supports two different models: current source and voltage source models. In our case we use a current source model which has as inputs $\mathrm{d}-\mathrm{q}$ axis reference current coming from the controller and cosref and sinref signals from a PLL model.

Fig. 9 b) shows the schematic structure of the PV System model, developed for time-domain simulations where a DSL model is required, including Photovoltaic Model, DC-Link Model, PLL block and Static Generator with its Controller. The Static Generator is an easy to use model of any kind of static (non rotating) generators. Applications are PV Generators, Storage devices, wind generators etc. The PV system frame also contains the measurements blocks used as inputs for different components of the model. For instance, the Photovoltaic Model has as inputs irradiation $G$ and cell temperature tempCell, obtained from MATLAB-Simulink model considering the tilt angle, orientation and the influence of solar irradiation and wind speed on the cell temperature, implemented as a look-up table, as can be seen in Fig. 10a). Also the MPP of current, power and voltage as a function of time for one module are shown. 
In Fig. 9 c) it is shown the VRB system block diagram developed for time-domain simulations (RMS and EMT). The battery energy storage system contains the model of VRB, developed in DSL using the same equations like in Simulink model presented in the last section and the charge/discharge controller which takes in consideration the SOC level of the battery, DC current and voltage of the cell stacks and provides the current set-point for the inverter. Also, to study the system stability the frequency and power controllers have been implemented.

In order to validate the simulation model developed in PowerFactory and to compare the results with MATLABSimulink model, the same measurements have been used like in the last section when we compare the results of Simulink model with experiments (Fig. 8).

As can be seen in Fig. 11 a) the simulation results of DC Voltage and Power for different SOC level are similar. Also, to point out the accuracy of the simulation model developed in PowerFactory in Fig. 11 b) is depicted a comparison between simulated and measured SOC level.

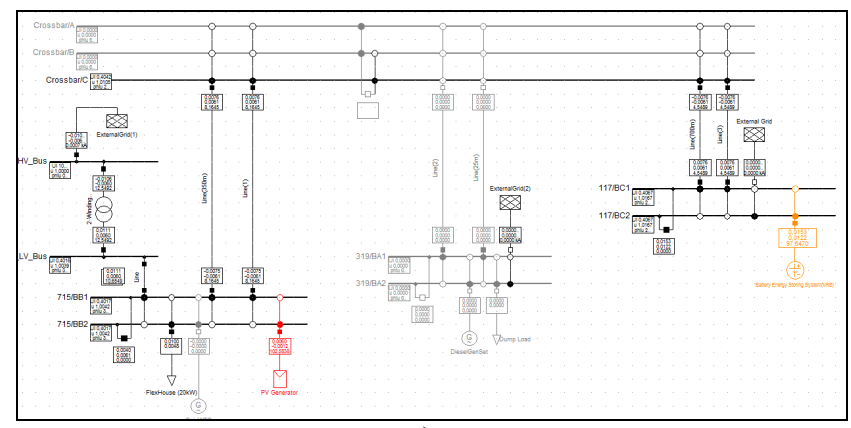

a)
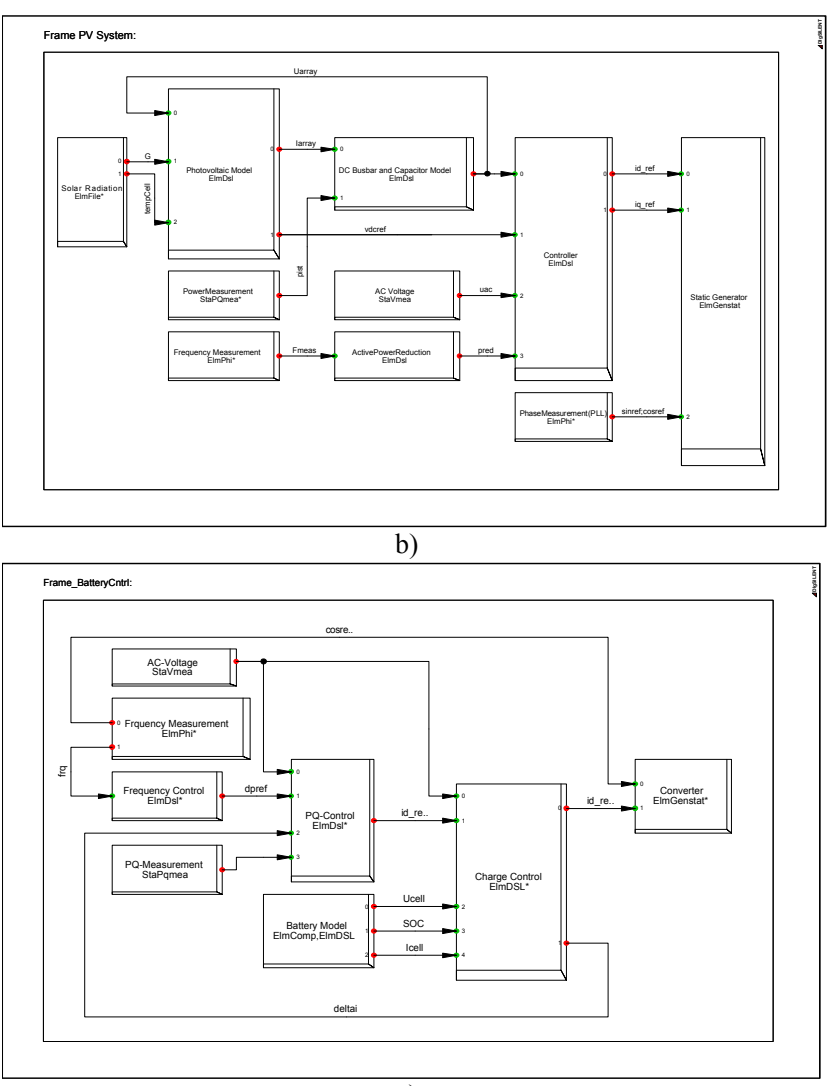

c)

Fig. 9. a) Single line diagram of SYSLAB configuration, b) schematic block diagram of the PV system model and c) VRB system implemented in PowerFactory.
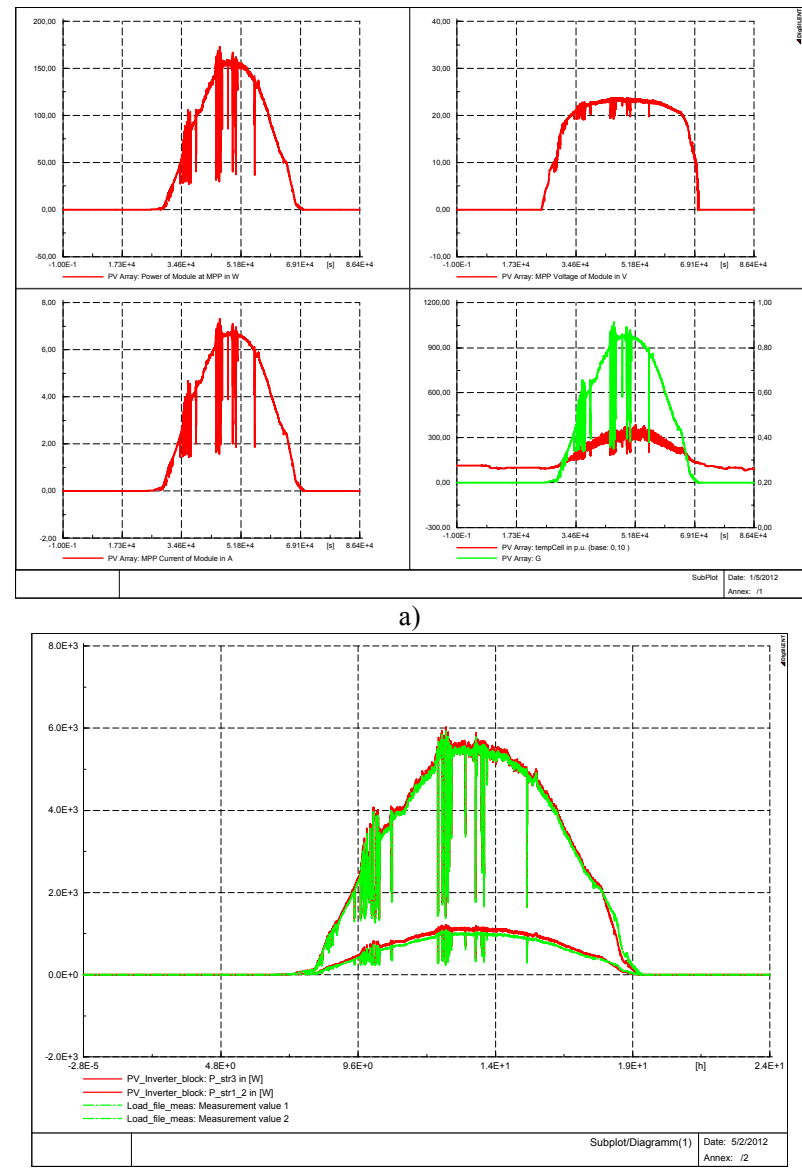

b)

Fig. 10. Simulation results of the PV system model, a) and a comparison between simulations and measurements, $\mathrm{b}$ ).
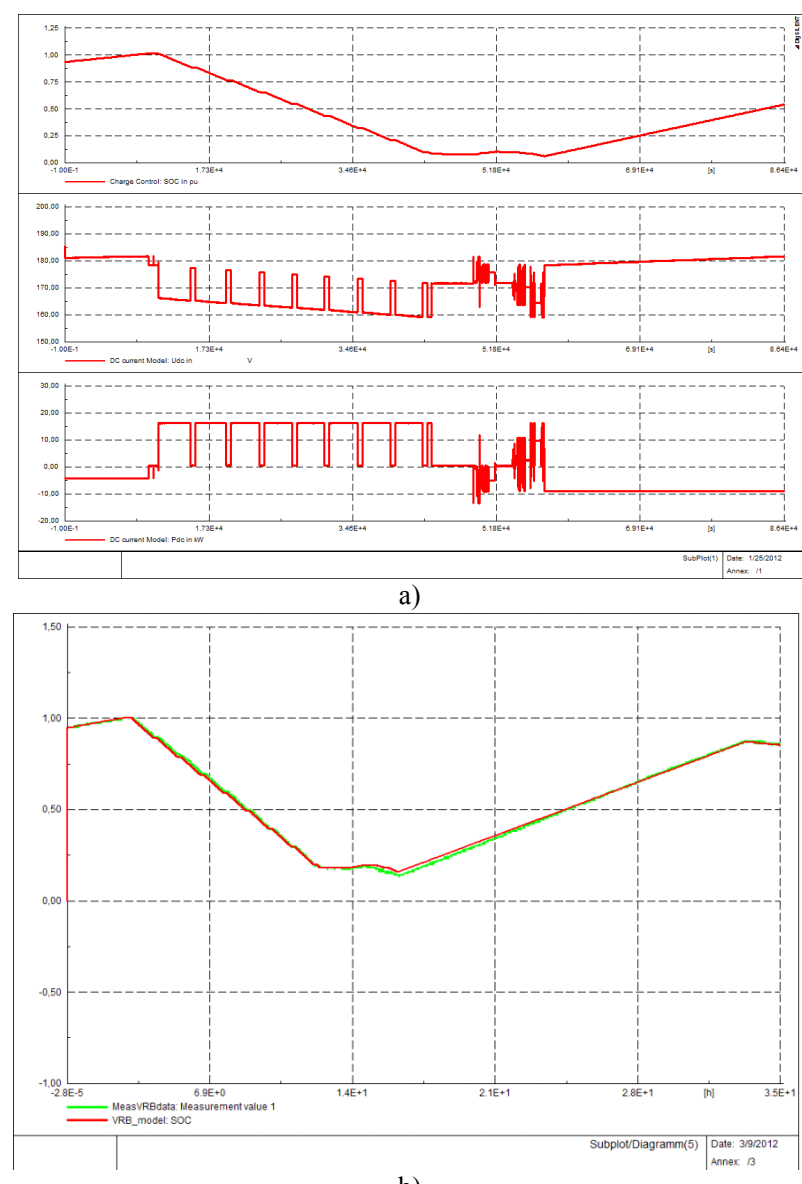

Fig. 11. Simulation results of the VRB system model, a) and a comparison between simulated and measured SOC level, b). 


\section{CONCLUSIONS}

This paper proposes the development and implementation of simulation tools to analyze and simulate power systems with renewable energy sources and electricity storage. The tools are based on models validated by measurements.

A four-parameter model of a PV panel and a PV system, implemented in MATLAB/Simulink, using data provided by the manufacturer with semi-empirical equations to predict the PV characteristics for any condition. The PV characteristics are modeled according to a single diode four parameter equivalent circuit and according to PV parameters values taken from the manufacturer technical data.

The paper also proposes a data processing simulation model that relies on ambient data from a local weather station, like most common in a real situation, not from sensors mounted on the PV panels. The model calculates the cell temperature and the solar irradiance on the PV panels considering, among others, the tilt angle, the orientation of the panels, and the wind cooling effect. The paper shows that these factors significantly influence the power output from the PV panels.

The VRB system model has been developed and implemented first in MATLAB-Simulink considering the efficiency and the power losses of different components. The characteristics of the battery have been computed based experiments by measuring electrical parameters at different loads and SOC levels.

Comparison with experimental data, acquired by SCADA system and processed by MATLAB, and with the characteristics of the PV panels and VRB, provided by manufacturers, has shown that the models implemented in MATLAB/Simulink can be an accurate simulation tool to study and analyze the characteristics of individual units and for the prediction of energy production with energy storage systems.

A PV system model and a VRB system model, using the same equations and parameters as in MATLAB/Simulink has also been developed and implemented in PowerFactory to study load flow, steady-state voltage stability and dynamic behavior of a distributed power system. Also, the simulation results have shown a good similarity between both tools.

\section{REFERENCES}

[1] Energynautics GmbH, Longen, Germany, 2010. Available: www.energynautics.com

[2] S. Seme, G. Stumberg, and J. Vorsic, "Maximum efficiency trajectories of a two-axis sun tracking system determined considering tracking system consumption," IEEE Trans. On Power Electronics, vol. 26, no. 4, pp. 1280-1290, Apr. 2011.

[3] W. De. Soto, S. A. Klein, and W. A. Beckman, "Improvement and validation of a model for photovoltaic array performance," ELSEVIER Solar Energy, vol. 80, pp. 78-88, 2006.

[4] Y. Riffonneau, S. Bacha, S. Barruel and S. Ploix, "Optimal Power Management for grid connected PV Systems with batteries", IEEE Transaction on Sustainable Energy, vol. 2, no. 3, pp. 309-320, July 2011.

[5] J E. Skoplaki, A. G. Boudouvis and J. A. Polyvos, "A simple correlation for the operating temperature of photovoltaic modules of arbitrary mounting", ELSEVIER Solar Energy Materials, pp. 1393$1402,2008$.

[6] K. Murat, S. Mehmet, B. Yunus, D. Sedat, "Determining optimum tilt angles and orientations of photovoltaic panels in Saliurfa", IEEE Transaction on Renewable Energy, vol. 29, issue 8, pp. 1265-1275, 2004.

[7] H. Jiayi, J. Chuanwen, and X. Rong, "A review on distributed energy resources and MicroGrid", ELSEVIER Renewable \& Sustainable Energy Reviews, vol. 12, pp. 2472-2483, 2008.
[8] M. G. Villalva, J. R. Gazoli, E. R. Filho, "Comprehensive Approach to Modelling and Simulation of Photovoltaic Arrays", IEEE Transaction on Power Electronics, vol. 24, issue: 5, pp. 1198-1208, 2009.

[9] D. Y. Goswani, Principles of Solar Engineering, (2 ${ }^{\text {nd }}$ ed.), Philadelphia: Taylor \& Francis, 2000, p. 81-98.

[10] M. Jansen, R. Louie, M. E. Amoli and F. Sami, "Model and simulation of a 75 kW PV solar array", in Proc. 2010 IEEE PES Transmission and Distribution Conference and Exposition, pp. 1-5.

[11] S. Dezso, R. Teodorescu and P. Rodriguez, "PV panel model based on datasheet values", in Proc. 2007 IEEE International Symposium on Industrial Electronics, pp. 2392-2396.

[12] H. Liu, L. Jin, D. Le and A. A. Chowdhury, "Impact of high penetration of solar photovoltaic generation on power system small signal stability", in Proc. 2010 POWERCON, pp. 1-7.

[13] A.D. Hansen, P. Sørensen, L.H. Hansen, H. Bindner, "Models for a Stand-Alone PV System", Risø National Laboratory, Roskilde, RisøR-1219 (EN) / SEC-R-12, Dec. 2000.

[14] IEEE Standard for Interconnecting Distributed Resources with Electric Power Systems, IEEE Standard 1547-2008.

[15] H. Bidner, C. Ekman, O. Gehrke and F. Isleifsson, "Characterization of Vanadium Flow Battery", Riso-R-1753 Report, Roskilde, Denmark, October 2010.

[16] L. Barote, R. Weissbach, R. Teodorescu, C. Marinescu, M. Cirstea, "Stand-Alone Wind System with Vanadium Redox Battery Energy Storage", IEEE, International Conference on Optimization of Electrical and Electronic Equipments, OPTIM'08, pp. 407-412, 22-24 May 2008, Brasov, Romania.

[17] W. Wang, B. Ge, D. Bi and D. Sun, "Grid-Connected Wind Farm Power Control using VRB-based Energy Storage System", IEEE Transaction on Energy Conversion, pp.3772-3777, 2010.

[18] DIgSILENT PowerFactory, User's Manual and Tutorial-Version 14.1, Gomaringen-Germany, November 2011.

[19] Schuco S 165-SPU, Data sheet and technical data of the Photovoltaic Module.

[20] L. Mihet-Popa, C. Koch-Ciobotaru, F. Isleifsson and H. Bindner, „Development of tools for simulation systems in a distribution network and validated by measurements", the 13th International Conference on Optimisation of Electrical and Electronic Equipment, OPTIM 2012, May 24-26, Brasov-Romania, pp. 1022-1031.

[21] F. Genduso, R. Miceli and G. Ricco-Galluzzo, "Flexibile Power Converters for the Fault Tolerant Operation of Micro-Grids", XIX International Conference on Electrical Machines-ICEM 2010, Rome.

\section{BIOGRAPHIES}

Lucian Mihet-Popa received the B.S. degree, M.S. degree and Ph.D. degree from the POLITEHNICA University of Timisoara, Romania, in 1999, 2000 and 2003, respectively, all in electrical engineering. He is currently working as a Scientist with the Department of Electrical Engineering-DTU since 1st March 2011. He is also an Associate Professor in the Department of Electrical Engineering at POLITEHNICA University of Timisoara. Dr. Mihet-Popa received in 2005 the second prize paper award of the IEEE Industry Applications Society. His research interest includes control and modeling of DER components in micro grids, electrical machines and drives, detection and diagnosis of faults, especially for wind turbine applications.

Cosmin Koch-Ciobotariu was born in Arad, Romania, in 1985. He received the B.E. degree in Automation and Computer Science at Politehnica University of Timisoara in 2009. He is currently working towards the Ph.D. degree. His interests include control systems, renewable energy, and energy storage.

Fridrik Rafn Isleifsson received the M.sc. degree in electrical engineering from the Technical University of Denmark in 2006. He is currently a Ph.D. student with the Intelligent Energy System Programmed at the Technical University of Denmark. His research focuses on demand side participation in providing ancillary services to the power system and implementation of control strategies in laboratory demonstrations.

Henrik W. Bindner was born on 30 June 1964 in Copenhagen, Denmark. $\mathrm{He}$ received his master in electrical engineering from the Technical University of Denmark in 1988. Since 1990 he has been with Risø DTU National Laboratory for Sustainable Energy in the Wind Energy Division, currently as a Senior Scientist. He has mainly been working on integration of wind energy into power system. Currently, he is researching how distributed energy resources can be applied to increase penetration of wind energy. 